\title{
Desempenho, morfometria duodenal e histopatologia do fígado de frangos de corte alimentados com dietas contendo diferentes níveis de selênio orgânico em condições de estresse calórico ${ }^{1}$
}

\author{
Performance, duodenal morphology and histopathology of broiler liver fed diets containing \\ different levels of organic selenium in heat stress conditions
}

\author{
CARVALHO, Genilson Bezerra de ${ }^{2^{*}}$; LOPES, João Batista ${ }^{3}$; SILVA, Sandra Regina Gomes \\ $\mathrm{da}^{4}$; DOURADO, Leilane Rocha Barros ${ }^{5}$; MIRANDA, Dayane Francisca Higino ${ }^{4}$; COSTA, \\ Francisco Assis Lima ${ }^{6}$
}

\footnotetext{
${ }^{1}$ Pesquisa Financiada pelo EDITAL FAPEPI/MCT/CNPq N ${ }^{\circ}$. 006/2011.

${ }^{2}$ Universidade Federal de Goiás, Departamento de Produção Animal, Programa de Pós-Graduação em Zootecnia, Goiânia, Goiás, Brasil.

${ }^{3}$ Universidade Federal do Piauí, Centro de Ciências Agrárias, Departamento de Zootecnia, Teresina, Piauí, Brasil.

${ }^{4}$ Universidade Federal do Piauí, Centro de Ciências Agrárias, Programa de Pós-Graduação em Ciências Animal, Teresina, Piauí, Brasil.

${ }^{5}$ Universidade Federal do Piauí, Centro de Ciências Agrárias, Departamento de Zootecnia, Bom Jesus, Piauí, Brasil.

${ }^{6}$ Universidade Federal do Piauí, Centro de Ciências Agrárias, Departamento de Clínica e Cirurgia Veterinária, Teresina, Piauí, Brasil.

*Endereço para correspondência: ge.nilson.bezerra@hotmail.com
}

\section{RESUMO}

A pesquisa foi desenvolvida para avaliar o desempenho, a morfometria duodenal e as alterações histopatológicas do fígado de frangos de corte, alimentados com dietas contendo diferentes níveis de selênio $(0,5 ; 1,1 ; 1,7 ; 2,3 ; 2,9$ e $3,5 \mathrm{ppm}$ de $\mathrm{Se} / \mathrm{kg}$ de ração), criados no período de 1 a 21 dias de idade, em condições de estresse calórico. As aves receberam dietas isonutritivas à base de milho e farelo de soja, formuladas para atender as exigências nutricionais, exceto para o selênio. A partir de uma dieta basal foi feita a suplementação do selênio, com o uso de selenometionina (SelPlex $\left.{ }^{\circledR}\right)$. Setecentos e vinte pintos da linhagem Ross 308, mistos, foram utilizados em delineamento de blocos casualizados, com seis tratamentos e seis repetições com vinte aves por unidade experimental. $\mathrm{O}$ ambiente interno dos galpões foi avaliado com base no Índice de Temperatura de Globo Negro e Umidad e (ITGU), no Índice de Temperatura e U midade (ITU) e Temperatura Efetiva (TE). $\mathrm{O}$ uso da suplementação de selênio orgânico na alimentação de frangos de corte melhora a conversão alimentar, mas, não interfere nos parâmetros comprimento de cripta e altura de vilosidade e não promove reação inflamatória no fígado destes, nos níveis testados.

Palavras-chave: aves, calor, nutrição, minerais orgânicos

\section{SUMMARY}

The research was conducted to evaluate the performance, duodenal morphology and histopathological changes in the liver of broilers fed diets containing different levels of selenium $(0.5,1.1,1.7,2.3,2,9$ and $3.5 \mathrm{ppm} \mathrm{Se} / \mathrm{kg}$ diet $)$, created in the period 1-21 days old, under heat stress conditions. The birds were isonutritives diets based on corn and soybean meal, formulated to meet the nutritional requirements, except for selenium. From a basic diet supplementation of selenium was taken, such as use of selenomethionine (Sel - Plex $\left.{ }^{\circledR}\right)$. Seven hundred and twenty chicks of mixed lineage Ross 308, were used in a randomized complete block design 
with six treatments and six replicates of twenty birds each. The internal environment of the sheds was evaluated based on the Temperature Index Black Globe Humidity (BGT), the Temperature and Humidity Index (THI) and Effective Temperature (ET). The use of organic selenium supplementation in the diet of broilers improves feed conversion, but does not interfere in the length parameter crypt and villus height and does not promote inflammation in the liver of these, in both levels.

Keywords: broiler, heat, nutrition, organic minerals

\section{INTRODUÇ̃̃O}

A evolução da avicultura brasileira tem sido bem representativa, com as aves apresentando respostas eficientes e compatíveis com as criações de alto padrão tecnológico dos países desenvolvidos. Esse crescimento encontra-se pautado nos grandes avanços, nas diferenciadas área do setor produtivo: genética, nutrição, sanidade, ambiência e manejo.

$\mathrm{Na}$ nutrição avícola, os minerais desempenham relevantes e diversificadas funções como constituintes estruturais, transmissores de impulsos nervosos, reguladores da digestão dos alimentos, elementos ativos do metabolismo e como componentes estruturais e cofatores de enzimas, auxiliando na alteração ou modulação alostérica da estrutura terciária das enzimas, tornando-as ativas ou inativas (MOREIRA et al., 2009).

Dentre os minerais, o selênio $(\mathrm{Se})$ é um elemento conhecido como um nutriente essencial a mais de 40 anos, e tem se destacado pelas ações desempenhadas no sistema de defesa antioxidante, protegendo o organismo do stress oxidativo (PAPPAS et al, 2008;. ZOIDIS et al., 2010).

A utilização de microminerais na forma orgânica, ou seja, complexados a algum tipo de estrutura orgânica, é hoje bastante estudada, sendo essas fontes desempenhando importância fisiológica e de aspectos positivos na produtividade de aves comerciais. $\mathrm{O}$ selênio quando usado acima de determinados limites, pode constituir-se em problema para o organismo animal, com destaque para intoxicação, interação com outros minerais, baixa eficiência para a produção de carne. Por outro lado, a baixa retenção corporal do selênio promove sinais de deficiência do animal, em um espaço de tempo muito curto.

$\mathrm{Na}$ avicultura outro grande problema é o estresse térmico, pois está associado com o comprometimento no desempenho e produtividade das aves devido a declínios no consumo de ração, utilização de nutrientes, taxa de crescimento e eficiência alimentar.

Diversos estudos mostram os efeitos negativos do estresse térmico sobre o desempenho de frangos de corte, sendo que o calor é apontado como maior colaborador para tal queda (OBA et al., 2012).

Dessa forma, o trabalho foi desenvolvido com o intuito de avaliar o desempenho, a morfometria duodenal e as alterações histopatológicas do fígado, de frangos de corte, alimentados com dietas contendo diferentes níveis de selênio orgânico, criados no período de 1 a 21 dias de idade, em condições de estresse calórico.

\section{MATERIAL E MÉTODOS}

O experimento foi conduzido, no Setor de Avicultura do Departamento de Zootecnia do Centro de Ciências Agrárias da Universidade Federal do Piauí, no município de Teresina - Piauí.

Para a realização do ensaio de desempenho no período de 1 a 21 dias de idade, foram utilizados 720 pintos de corte, mistos, da linhagem Ross 308, de um dia de idade, em delineamento em 
blocos casualizados, com seis tratamentos e seis repetições de vinte aves cada.

As variáveis ambientais, temperatura e umidade relativa do ar no interior do galpão foram medidas, com termohigrômetro, colocado à altura intermediária, em relação aos boxes e termômetro de globo negro para obtenção do Índice de Temperatura do Globo e Umidade (ITGU) segundo Buffigton et al. (1981). As leituras das temperaturas e umidade foram realizadas duas vezes ao dia, durante todo o período experimental.

As aves foram alojadas em aviário de alvenaria, com pé direito de $2,80 \mathrm{~m}$ e cobertura com telhas de cerâmica, provido de lanternim, divididos em boxes separados com telas dispondo cada um, de uma área de $3,0 \mathrm{~m}^{2}$, dotados de bebedouros pendulares automáticos e comedouros tubulares tipo balde com piso de cimento coberto de casca de arroz.

$\mathrm{O}$ manejo dos animais foi similar ao recomendado pelo manual de criação da linhagem Ross para a fase de 1 a 21 dias, sendo as aves vacinadas contra as doenças de Marek, Newcastle e Gumboro de acordo com o programa de vacinação recomendado para a região.

Os tratamentos utilizados foram: dieta controle, somente com selênio inorgânico contido no suplemento mineral vitamínico, com o nível de 0,5ppm de Se inorgânico; demais tratamentos foram suplementação de Se orgânico nos níveis de: 1,$1 ; 1,7 ; 2,3 ; 2,9$ e $3,5 \mathrm{mg}$ de Se orgânico/ $\mathrm{Kg}^{-1}$ de ração. O selênio foi suplementado na forma de selenometionina (Sel-Plex $\left.{ }^{\circledR}\right), \quad$ pela substituição nas dietas pelo material inerte.

As dietas experimentais foram formuladas à base de milho e farelo de soja (Tabela 1 e 2), de forma a atender às necessidades nutricionais recomendadas por Rostagno et al. (2011). As rações experimentais para o período de 1 a 7 dias de idade (Tabela 1) foram preparadas manualmente e a da fase de 8 a 21 dias (Tabela 2), em um misturador horizontal com capacidade para $250 \mathrm{~kg}$. As rações e a água foram fornecidas à vontade, durante todo $\mathrm{o}$ experimento.

Durante o período experimental, foi adotado um programa de luz contínuo (24 horas de luz natural + artificial), visando manter a temperatura ambiente próxima de $32^{\circ} \mathrm{C}$, enquanto nas semanas subsequentes, a temperatura foi controlada com o intuito de provocar uma queda gradual de $2^{\circ} \mathrm{C} /$ semana, até atingir a temperatura ambiente.

No início do experimento, as aves foram pesadas e distribuídas, tomando como base o peso médio do lote, com o objetivo de obter uma homogeneidade das aves nos tratamentos. Foi estabelecida uma rotina diária de observação de todo lote, anotação das aves mortas e descartadas, bem como de seus pesos e registro de todos os acontecimentos referentes aos pintos, bem como lavagem dos bebedouros e limpeza do galpão experimental. Os comedouros e bebedouros foram colocados em alturas ideais, de acordo com o desenvolvimento dos animais.

Para proteger os pintos do vento sul (frio) e mantê-los aquecidos, foram utilizadas cortinas de polietileno ao redor do galpão experimental, permanecendo fechadas nas horas mais frias. De acordo com a temperatura ambiente e o comportamento das aves, as cortinas eram abertas gradativamente.

As variáveis de desempenho (consumo de ração, ganho de peso e a conversão alimentar), foram avaliadas para as fases de criação estudadas, sendo calculadas por meio de pesagens das aves e quantificações das rações, feito no primeiro e último dia de cada fase.

Os dados de desempenho zootécnico foram submetidos à análise de variância e de regressão de acordo com o procedimento GLM do SAS (1996), $\operatorname{com} \alpha=0,05$. 
Tabela 1. Composição em ingrediente e nutricional das dietas experimentais para fase de 1 a 7 dias de idade

\begin{tabular}{|c|c|c|c|c|c|c|}
\hline \multirow{2}{*}{ Ingredientes } & \multicolumn{6}{|c|}{ Níveis de Selênio (mg. $\left.\mathrm{Kg}^{-1}\right)$} \\
\hline & 0,5 & 1,1 & 1,7 & 2,3 & 2,9 & 3,5 \\
\hline Milho & 54,270 & 54,270 & 54,270 & 54,270 & 54,270 & 54,270 \\
\hline Farelo de soja (45\% PB) & 38,842 & 38,842 & 38,842 & 38,842 & 38,842 & 38,842 \\
\hline Óleo de soja & 2,500 & 2,500 & 2,500 & 2,500 & 2,500 & 2,500 \\
\hline Fosfato bicálcico & 1,910 & 1,910 & 1,910 & 1,910 & 1,910 & 1,910 \\
\hline Calcário calcítico & 0,910 & 0,910 & 0,910 & 0,910 & 0,910 & 0,910 \\
\hline Sal comum & 0,325 & 0,325 & 0,325 & 0,325 & 0,325 & 0,325 \\
\hline L-Lisina HCL 78\% & 0,265 & 0,265 & 0,265 & 0,265 & 0,265 & 0,265 \\
\hline DL-metionina 99\% & 0,228 & 0,228 & 0,228 & 0,228 & 0,228 & 0,228 \\
\hline Suplemento mineral vitamínico ${ }^{1}$ & 0,400 & 0,400 & 0,400 & 0,400 & 0,400 & 0,400 \\
\hline Material inerte $^{2}$ & 0,350 & 0,290 & 0,230 & 0,170 & 0,110 & 0,050 \\
\hline Material inerte $^{3}$ & 0,000 & 0,060 & 0,120 & 0,180 & 0,240 & 0,300 \\
\hline Total & 100,00 & 100,00 & 100,00 & 100,00 & 100,00 & 100,00 \\
\hline \multicolumn{7}{|c|}{ Composição calculada } \\
\hline Proteína Bruta (\%) & 22,207 & 22,207 & 22,207 & 22,207 & 22,207 & 22,207 \\
\hline Energia metabolizável (Mcal/kg) & 2,955 & 2,955 & 2,955 & 2,955 & 2,955 & 2,955 \\
\hline Cálcio $(\%)$ & 0,921 & 0,921 & 0,921 & 0,921 & 0,921 & 0,921 \\
\hline Fósforo Disponível (\%) & 0,471 & 0,471 & 0,471 & 0,471 & 0,471 & 0,471 \\
\hline Lisina Dig. Aves (\%) & 1,311 & 1,311 & 1,311 & 1,311 & 1,311 & 1,311 \\
\hline Met.+Cist. Dig. Aves (\%) & 0,813 & 0,813 & 0,813 & 0,813 & 0,813 & 0,813 \\
\hline Metionina Dig. Aves (\%) & 0,512 & 0,512 & 0,512 & 0,512 & 0,512 & 0,512 \\
\hline
\end{tabular}

${ }^{1}$ Suplemento mineral vitamínico contendo: Ácido fólico 200,00 mg; Ácido pantotênico 3.120,00 mg; Biotina 10,00 mg; Clorohidroxiquinolina 7.500,00 mg; Cobre 1.997,00 mg; Colina 78,10 g; Ferro 11,25 g; Iodo 187,47 mg; Manganês 18,74 g; Monensina 25,00 g; Niacina 8.400,00 mg; Selênio 75,00 mg; Vit. A 1680000,00 ui; Vit. B1 436,50 mg; Vit. B12 2400,00 mcg; Vit. B2 1.200,00 mg; Vit. B6 624,00 mg; Vit. D3 14000000 ui; Vit. E 13.500,00 ui; Vit. K3 360,00 mg; Zinco 17,50 g, Excipiente q.s.p., $1000 \mathrm{~g}$.

${ }^{2}$ Celite TM.

${ }^{3}$ Sel-Plex. 
Tabela 2. Composição em ingrediente e nutricional das dietas experimentais para fase de 8 a 21 dias de idade

\begin{tabular}{|c|c|c|c|c|c|c|}
\hline \multirow{2}{*}{ Ingredientes } & \multicolumn{6}{|c|}{ Níveis de Selênio $\left(\mathrm{mg} \cdot \mathrm{Kg}^{-1}\right)$} \\
\hline & 0,5 & 1,1 & 1,7 & 2,3 & 2,9 & 3,5 \\
\hline Milho & 58,473 & 58,473 & 58,473 & 58,473 & 58,473 & 58,473 \\
\hline Farelo de soja (45\% PB) & 35,196 & 35,196 & 35,196 & 35,196 & 35,196 & 35,196 \\
\hline Óleo de soja & 2,440 & 2,440 & 2,440 & 2,440 & 2,440 & 2,440 \\
\hline Fosfato bicálcico & 1,505 & 1,505 & 1,505 & 1,505 & 1,505 & 1,505 \\
\hline Calcário calcítico & 0,925 & 0,925 & 0,925 & 0,925 & 0,925 & 0,925 \\
\hline Sal comum & 0,325 & 0,325 & 0,325 & 0,325 & 0,325 & 0,325 \\
\hline L-Lisina HCL & 0,200 & 0,200 & 0,200 & 0,200 & 0,200 & 0,200 \\
\hline DL-metionina $99 \%$ & 0,186 & 0,186 & 0,186 & 0,186 & 0,186 & 0,186 \\
\hline Suplemento mineral vitamínico ${ }^{1}$ & 0,400 & 0,400 & 0,400 & 0,400 & 0,400 & 0,400 \\
\hline Material inerte ${ }^{2}$ & 0,350 & 0,290 & 0,230 & 0,170 & 0,110 & 0,050 \\
\hline Selênio orgânico ${ }^{3}$ & 0,000 & 0,060 & 0,120 & 0,180 & 0,240 & 0,300 \\
\hline \multirow[t]{2}{*}{ Total } & 100,00 & 100,00 & 100,00 & 100,00 & 100,00 & 100,00 \\
\hline & \multicolumn{6}{|c|}{ Composição calculada } \\
\hline Proteína Bruta $(\%)$ & 20,805 & 20,805 & 20,805 & 20,805 & 20,805 & 20,805 \\
\hline Energia metabolizável (Mcal/kg) & 3,001 & 3,001 & 3,001 & 3,001 & 3,001 & 3,001 \\
\hline Cálcio $(\%)$ & 0,819 & 0,819 & 0,819 & 0,819 & 0,819 & 0,819 \\
\hline Fósforo Disponível (\%) & 0,391 & 0,391 & 0,391 & 0,391 & 0,391 & 0,391 \\
\hline Lisina Dig. Aves (\%) & 1,174 & 1,174 & 1,174 & 1,174 & 1,174 & 1,174 \\
\hline Met.+Cist. Dig. Aves (\%) & 0,744 & 0,744 & 0,744 & 0,744 & 0,744 & 0,744 \\
\hline Metionina Dig. Aves (\%) & 0,458 & 0,458 & 0,458 & 0,458 & 0,458 & 0,458 \\
\hline
\end{tabular}

'Suplemento mineral vitamínico contendo: Ácido fólico 162,50 mg; Ácido pantotenico 2.600,00 mg; Clorohidroxiquinolina 7.500,00 mg; Cobre $1996,00 \mathrm{mg}$; Colina 71,59 g; Ferro 11,25 g; Iodo 187,47 mg; Manganês 17,74 g; Niacina 7,00 mg; Salinomicina 16,50 g; Selênio 75,00 mg; Vit. A 14,00062,50 ui; Vit. B1 388,00 mg; Vit. B12 2.000,00 mcg; Vit.B2 1.000,00 mg; Vit. B6 520,00 mg; Vit. D3 300012,00 ui; Vit. E 2.500,00 ui; Vit. K3 300,00 mg; Zinco 17,50 g, Excipiente q.s.p., 1000 g.

${ }^{2}$ Celite TM.

${ }^{3}$ Sel-Plex. 
Para análise histomorfométrica do intestino delgado e exame histopatológico de fragmentos de fígado, aos 21 dias de idade, foi utilizada uma ave por boxe, selecionada pelo peso médio da parcela, totalizando seis aves por tratamento. O segmento do intestino (duodeno) foi aberto pela região mesentérica $\mathrm{e}$ fragmentos desse tecido, de $0,5 \mathrm{~cm}$ de comprimento, e do fígado, de aproximadamente $0,5 \mathrm{~cm}$ de espessura, foram cuidadosamente coletados e fixados em formol a $10 \%$ tamponado com fosfato $0,01 \mathrm{M} \mathrm{pH} \mathrm{7,4.}$

Os tecidos foram processados por técnica de rotina, cortados com 3 a $4 \mu \mathrm{m}$ de espessura e corados com hematoxilinaeosina para análises morfométricas das vilosidades e criptas e histopatológicas dos fígados em microscopia de luz.

Para a quantificação de focos inflamatórios no fígado foram capturados 30 campos por fragmento de tecido hepático. Para a mensuração das criptas e vilosidades intestinais foram capturados 10 criptas e 10 vilosidades por animal. Foram selecionados e medidos os comprimentos em linha reta, de acordo com a unidade adotada $(\mu \mathrm{m}), 10$ criptas e 10 vilosidades bem orientadas, de cada região duodenal do intestino, por animal. As medidas de altura de vilosidades foram tomadas a partir da base superior da cripta até o ápice da vilosidade e as criptas foram medidas entre as vilosidades da base inferior até a base superior.

A quantificação foi realizada utilizando-se analisador de imagem computadorizado Leica Qwin D-1000, versão 4.1 (Cambridge, UK) do Setor de Patologia animal (BIOLAI) do Centro de Ciências Agrárias da Universidade Federal do Piauí.

Os resultados da incidência de focos inflamatórios foram submetidos à análise de variância e teste de comparação de médias. Os dados de comprimentos das criptas e altura das vilosidades foram analisados por testes não paramétricos de Kruskal-Wallis. Adotou-se $\alpha \leq 0,05$.

\section{RESULTADOS E DISCUSSÃO}

Os valores médios de temperatura, tanto no turno da manhã quanto no da tarde (Tabela 3), indicam que o experimento, a partir da primeira semana foi desenvolvido em ambiente de elevadas temperatura e segundo Ferreira (2005) com os animais submetidos a estresse térmico cíclico, durante parte do dia.

Tabela 3. Valores médios da temperatura, UR, ITGU, ITU e TE no interior do galpão no período de 1 e 21 dias de idade de frangos de corte

\begin{tabular}{lcccccccc}
\hline Turno & Fase criação & TBS $\left({ }^{\circ} \mathrm{C}\right)$ & TBU $\left({ }^{\circ} \mathrm{C}\right)$ & TGN $\left({ }^{\circ} \mathrm{C}\right)$ & UR $(\%)$ & ITGU & ITU & TE \\
\hline Manhã & 1 a 21 dias & 26,5 & 23,7 & 27,0 & 82 & 77 & 77 & 25 \\
Tarde & 1 a 21 dias & 31,0 & 25,4 & 30,1 & 68 & 81 & 81 & 27 \\
\hline TBS = temperatura bulbo & seco; TBU & $=$ temperatura & bulbo úmido; & TGN = temperatura globo negro; \\
UR= umidade relativa do ar; ITGU $=$ índice de temperatura de globo e umidade; ITU= Indice de temperatura e \\
umidade; TE= temperatura efetiva.
\end{tabular}

As suplementações de selênio orgânico nas rações dos frangos de corte, no período de 1 a 21 dias de idade, influenciaram, de forma linear, o consumo de ração (CR) e a conversão alimentar (CA) (Tabela 4), segundo as respectivas equações: $\mathrm{CR}=1,04-0,028 \mathrm{NS}\left(\mathrm{R}^{2}=0,38\right.$, $\mathrm{P}<0,05) ; \mathrm{CA}=1,58-0,043 \mathrm{NS}\left(\mathrm{R}^{2}=0,50\right.$, 
$\mathrm{P}<0,01)$. No entanto, o ganho de peso não foi influenciado pelos níveis de selênio da dieta.

Dessa forma, observou-se que o uso do selênio, em doses crescentes, reduziu o consumo de ração sem afetar o ganho de peso, promovendo melhor conversão alimentar, mesmo em condições de elevadas temperaturas, devido ao melhor aproveitamento dos nutrientes.

Tabela 4. Desempenho de frangos de corte no período de 1 a 21 dias, em função dos níveis de selênio orgânico nas rações

\begin{tabular}{lccc}
\hline \multirow{2}{*}{ Níveis de Selênio $\left(\mathrm{mg} \mathrm{Kg}^{-1}\right)$} & \multicolumn{3}{c}{ Parâmetros de Desempenho } \\
\cline { 2 - 4 } & $\begin{array}{c}\text { Consumo ração } \\
(\mathrm{kg})\end{array}$ & $\begin{array}{c}\text { Ganho de Peso } \\
(\mathrm{kg})^{1}\end{array}$ & $\begin{array}{c}\text { Conversão alimentar } \\
(\mathrm{kg} / \mathrm{kg})^{2}\end{array}$ \\
\hline 0,5 & 1,017 & 0,659 & 1,54 \\
1,1 & 1,003 & 0,657 & 1,53 \\
1,7 & 1,045 & 0,666 & 1,57 \\
2,3 & 0,925 & 0,635 & 1,46 \\
2,9 & 0,918 & 0,664 & 1,38 \\
3,5 & 0,975 & 0,665 & 1,47 \\
\hline & Valor de P & Valor de P & Valor de P \\
\hline Linear & 0,0192 & 0,8420 & 0,0017 \\
Quadrático & 0,5452 & 0,4206 & 0,9688 \\
Cúbico & 0,0290 & 0,5209 & 0,0173 \\
Quarto Grau & 0,2605 & 0,6142 & 0,0570 \\
Quinto Grau & 0,0784 & 0,1020 & 0,3358 \\
\hline CV (\%) & 7,04 & 4,72 & 5,31 \\
\hline
\end{tabular}

Os dados de desempenho obtidos neste experimento não estão de acordo com os resultados obtidos por Medeiros et al. (2012) que mencionam não terem verificados diferenças para consumo de ração e conversão alimentar de frango de corte suplementados com Se na forma orgânica.

Funari Júnior et al. (2010), trabalhando com suplementação de 0,15 e $0,45 \mathrm{mg}$ $\mathrm{Se} / \mathrm{kg}$ de ração, tanto na forma orgânica, como inorgânica para frangos de corte, observaram que a fonte não influenciou o ganho de peso, porém observaram efeito dos níveis sobre os parâmetros de desempenho sendo que a suplementação de $0,45 \mathrm{mg} \mathrm{Se} / \mathrm{kg}$ de ração, proporcionou maior peso médio no período de 1 a 42 dias de criação.

Os resultados, também, são divergentes dos relatados encontrados em outras pesquisas desenvolvidas em diferentes condições, usando diferentes proporções ou formas de selênio na dieta. Analisando a exigência de selênio para frangos de corte, alimentados com dietas à base de milho e farelo de soja até os 21 dias de idade, Ali et al. (1997) não verificaram diferença para os parâmetros ganho de peso, consumo e conversão alimentar. No presente estudo a conversão alimentar melhorou com o incremento de selênio nas dietas. Ainda nesse contexto, avaliando diferentes níveis de selênio em rações para frangos de corte sob diferentes temperaturas, Dahlke et al. (2005) observaram que a suplementação de selênio na ração até $0,4 \mathrm{ppm}$ não influenciou o desempenho dos animais aos 21 e 42 dias de idade sob estresse por calor. Estes autores concluíram que a suplementação de selênio na forma 
orgânica, parece ser a melhor maneira de se obter um bom empenamento dos frangos de corte até os 21 dias de idade. Estudos realizados por Choct \& Naylor (2004), utilizando 0,1ppm de selênio, mostraram que esse nível não afetou o desempenho de frangos de corte. Boiago (2006), ao testar fontes inorgânica e orgânica de selênio (selenito de sódio e selenometionina) na ração de frangos de corte da linhagem Cobb, encontrou maior ganho de peso no grupo das aves alimentadas com a fonte orgânica.

$\mathrm{O}$ estudo histopatológico do fígado revelou que todos os grupos analisados apresentavam um infiltrado inflamatório, predominantemente, mononuclear, com presença de polimorfonuclear (heterófilos) e fibroblastos em menor proporção, de distribuição focal, de intensidade variando de discreta a moderada, com poucos casos revelando um infiltrado intenso. A lesão estava localizada principalmente no espaço porta, seguido de localização intralobular, com acúmulo de células inflamatórias bem definidas, constituído principalmente por macrófagos e eosinófilos, sugerindo formação granulomatosa.

Não houve diferença nos valores da incidência de focos inflamatórios no fígado entre os tratamentos $(\mathrm{P}>0,05)$, embora, em termos quantitativo, os dados mostram tendência de aumento da lesão com o incremento dos níveis de selênio (Figura 1) ate o nível de selênio de $2,9 \mathrm{mg}$ Se. $\mathrm{Kg}^{-1}$.

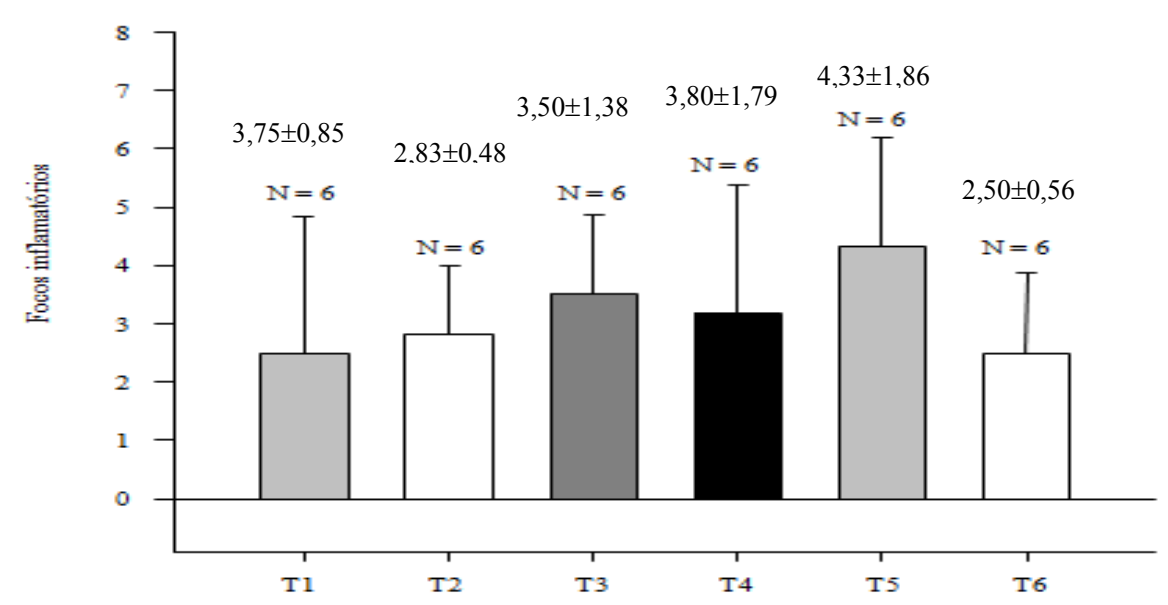

Legenda: T1 - 0,5mg Se. $\mathrm{Kg}^{-1}$; T2 - 1,1mg Se. $\mathrm{Kg}^{-1}$; T3 - 1,7mg Se.Kg ${ }^{1}$; $\mathrm{T} 4$ 2,3mg Se. $\mathrm{Kg}^{-1}$; T5 - 2,9mg Se. $\mathrm{Kg}^{-1}$; T6 - 3,5mg Se. $\mathrm{Kg}^{-1}$.

Figura 1. Incidência de focos inflamatórios em fígado (mediana) de frangos de corte, aos 21 dias de idade, alimentados com níveis de selênio orgânico na dieta.

O selênio possui margem muito estreita entre o nível ótimo e aquele capaz de causar intoxicação no animal (GIERUS, 2007), sendo essas lesões no fígado sugestivas de começo de intoxicação, podendo comprometer o desenvolvimento zootécnico dos animais. O NRC (1994) traz como recomendação de suplementação 0,150ppm de selênio para melhor desempenho dos frangos de corte, porém, algumas pesquisas tem evidenciado a necessidade de níveis mais elevados.

Minerais na forma orgânica, recentemente disponível no mercado, estão sendo 
estudados como forma mais biodisponível e atóxica para os animais. É importante ressaltar que o selênio é um micromineral que atua no sistema celular com função antioxidante, melhorando a resposta imunológica e contribuindo para o aumento da resistência às infecções, bem como atuando na manutenção da atividade dos hormônios hipofisário e as sínteses biológicas de degradação oxidativa.

A análise quantitativa do comprimento das criptas duodenais (Figura 2) de frangos de corte, alimentados com diferentes níveis de selênio orgânico na ração, apresentaram criptas mais preservadas no tratamento sem adição de selênio orgânico, apesar de não existir diferença significativa $(\mathrm{P}>0,05)$, entre os tratamentos. O uso de selênio acima do nível recomendado pode influenciar na morfologia intestinal das aves e ter como consequência, interferência negativa no desempenho zootécnico dos frangos de corte no período de 1 a 21 dias de idade. Nesta pesquisa este aspecto não foi evidenciado.

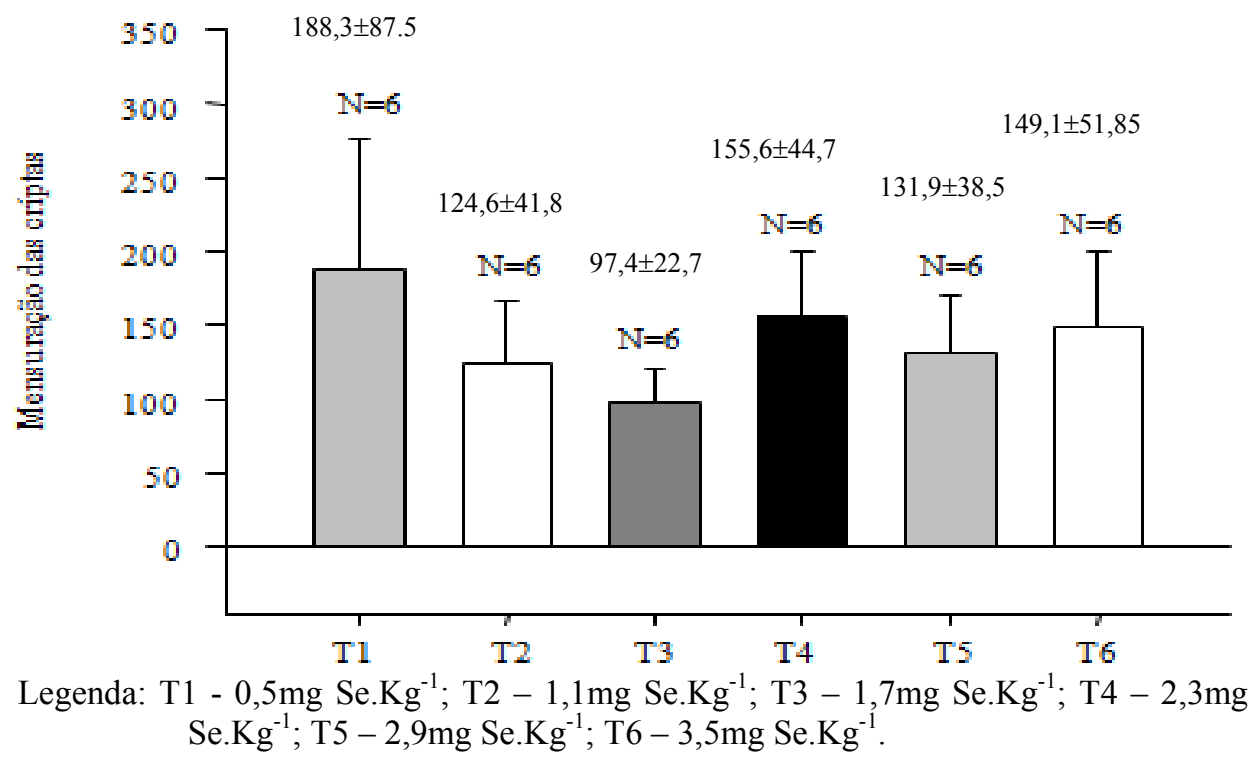

Figura 2. Análise quantitativa do comprimento das criptas duodenais $(\mu \mathrm{m})$ de frango de corte aos 21 dias de idade alimentados com níveis crescentes de selênio orgânico na dieta

A altura das vilosidades do duodeno de frangos de corte no período de 1 a 21 dias de idade, não apresentou diferença significativa entre os tratamentos $(\mathrm{P}>0,05)$, (Figura 3). É importante ressaltar que os níveis de selênio foram crescentes nas dietas experimentais.

O comportamento do comprimento das criptas foi semelhante ao da altura das vilosidades em resposta aos níveis de selênio orgânico das dietas. Os resultados da presente pesquisa se contrapõem aos encontrados por Saad (2009), ao constatarem que a altura das vilosidades no duodeno apresentou-se significativamente menor nos animais suplementados com selênio orgânico que no grupo controle, sendo que a profundidade das criptas apresentou-se menor aos 21 dias e maior aos 25 dias quando comparada com aquelas do grupo controle. 


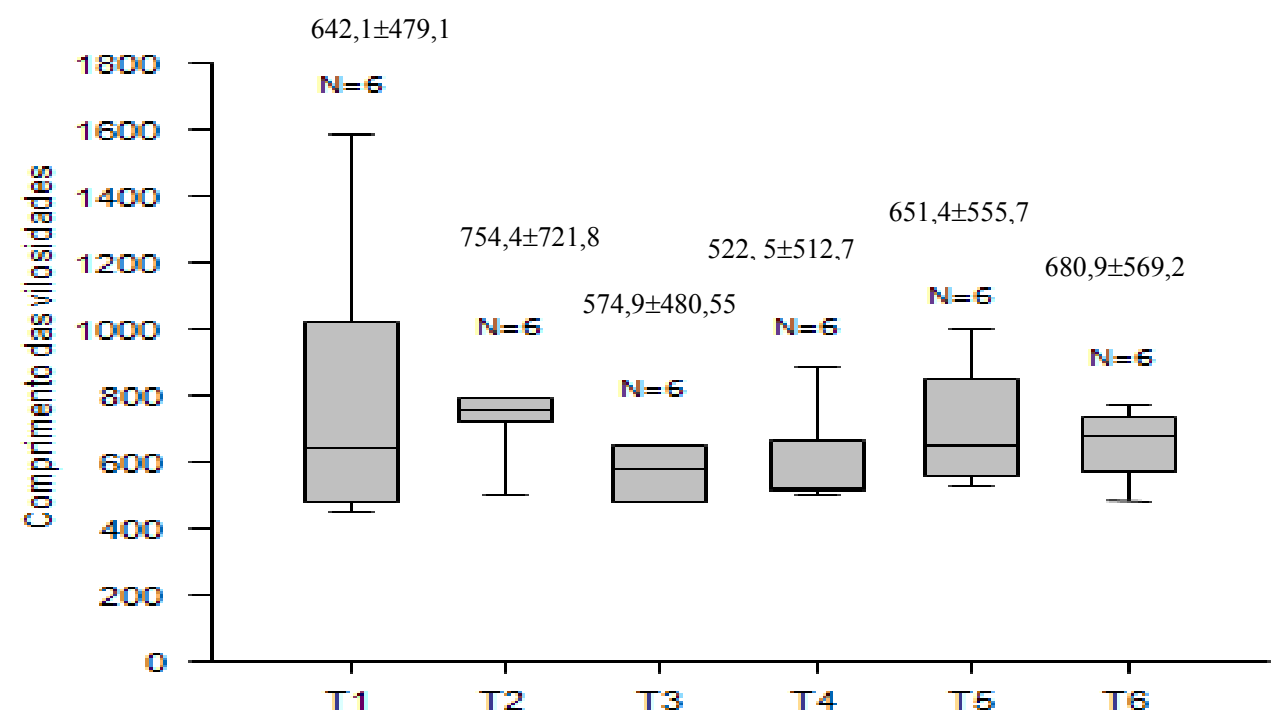

Legenda: T1 - 0,5mg Se. $\mathrm{Kg}^{-1}$; T2 - 1,1mg Se. $\mathrm{Kg}^{-1}$; T3 - 1,7mg Se. $\mathrm{Kg}^{-1}$; T4 2,3mg Se. $\mathrm{Kg}^{-1}$; T5 - 2,9mg Se. $\mathrm{Kg}^{-1} ; \mathrm{T} 6-3,5 \mathrm{mg} \mathrm{Se} . \mathrm{Kg}^{-1}$.

Figura 3. Análise quantitativa do comprimento das vilosidades intestinal $(\mu \mathrm{m})$ de frango de corte aos 21 dias de idade alimentados com níveis crescentes de selênio orgânico na dieta

Segundo Maiorka et al. (2002a,b) a altura de vilosidade está diretamente relacionada à maior capacidade de absorção e digestão de nutrientes e melhor desenvolvimento dos animais.

Os resultados de desempenho, em parte, estão em discordância com os resultados encontrados para o estudo histomorfométrico da mucosa intestinal, visto que as aves alimentadas com dietas com e sem selênio suplementar apresentaram, do ponto de visto estatístico, os mesmos valores para comprimento das criptas e altura da vilosidade e com relação ao desempenho, as aves suplementadas com selênio orgânico apresentaram menor consumos de ração e melhor conversão alimentar. Provavelmente, outros mecanismos de ação do selênio podem ter contribuído na eficiência alimentar em frangos de corte submetido a estresse por calor cíclico.

Nas condições em que este experimento foi conduzido, o uso da suplementação de selênio orgânico na alimentação de frangos de corte melhora a conversão alimentar, mas, não interfere nos parâmetros comprimento de cripta e altura de vilosidade e não promove reação inflamatória no fígado destes, nos níveis testados.

\section{REFERÊNCIAS}

ALI, J.; LEDOUX, D.R.; BERMUDEZ, A.J.; SUNDE, R.A. Selenium requiriment of broilers fed corn-soybean meal diets from day 1 to 21. Poultry Science, v.72, n.1, p.58, 1997.

BOIAGO, M.M. Características produtivas e qualitativas da carne de frangos alimentados com diferentes concentrações e fontes de selênio. 2006. 60f. Dissertação (Mestrado em Zootecnia) - Universidade Estadual Paulista, Faculdade de Ciências Agrárias e veterinárias, Jaboticabal. 
BUFFINGTON, D.E.; COLLAZO-

AROCHO, A.; CANTON, G.H. PITT, D.; HATCHER, W.W.; COLLIER R.J. Black globe-humidity index (BGHI) as comfort equation for dairy cows. Transaction of the ASAE, v.24, n.3, p.711-714, 1981.

CHOCT, M.; NAYLOR, J. The effect of dietary Se source and vitamin $\mathrm{E}$ levels on performance of male broilers. AsianAustralian Journal of Poultry Science, v.17, n.7, p.1000-1006, 2004.

DAHLKE, F.; GONZALES, E.; FURLAN, R.L.; GADELHA, A.C.; MAIORKA, A.; ALMEIDA, J.G.

Avaliação de diferentes fontes e níveis de selênio para frangos de corte em diferentes temperaturas. Archives of Veterinary Science, v.10, p.21-26, 2005.

FERREIRA, R.A. Maior produção com melhor ambiente para aves, suínos e bovinos. Viçosa, MG: Aprenda Fácil, 2005. 371p.

FUNARI JÚNIOR, P.; ALBUQUERQUE, R.; ALVES, F.R.; MURAROLLI, V.D.A.; TRINDADE NETO, M.A.; SILVA, E.M. Diferentes fontes e níveis de selênio sobre o desempenho de frangos de corte.

Brazilian Journal Veterinary Research Animal Science, v.47, n.5, p.380-384, 2010.

GIERUS, M. Fontes orgânicas e inorgânicas de selênio na nutrição de vacas leiteiras: digestão, absorção, metabolismo e exigências. Ciência Rural, v.37, n.4, p.1212-1220, 2007.

MAIORKA, A.; MACARI, M. Absorção de minerais. In: MACARI, M.; FURLAN, R. L.; GONZALES, E. (Eds.). Fisiologia aviária aplicada a frangos de corte. 2. ed. Jaboticabal: UNESP/FUNEP, 2002a. p.167-173.
MAIORKA, A.; BOLELI, I. C.; MACARI, M. Desenvolvimento e reparo da mucosa intestinal. In: MACARI, M.; FURLAN, R.. L.; GONZALES, E. Fisiologia aviária aplicada a frangos de corte. Jaboticabal: FUNEP/UNESP, 2002b. p.143-148.

MEDEIROS, L.G.; OBA, A.; SHIMOKOMAKI, M.; PINHEIRO, J.W.; SILVA, C.A.; SOARES, A.L.; PISSINATI, A.; ALMEIDA, M. Desempenho, características de carcaça e qualidade de carne de frangos de corte suplementados com selênio orgânico.

Semina: Ciências Agrárias, v.33, p.3361-3370, 2012.

MOREIRA, J.; LOPES, J.B.; VITTI, D.M. S.S.; TEIXEIRA, A.O. Modelos matemáticos para o estudo do fluxo biológico do fósforo em suínos alimentados com dietas suplementadas com níveis crescentes de fitase. Arquivo Brasileiro de Medicina Veterinária e Zootecnia, v.61, p.420-428, 2009.

NATIONAL RESEARCH COUNCIL NRC. Nutrient requirements of poultry. 9th ed. Revised. Washington: National Academy Press, 1994.

OBA, A.; LOPES, P.C.F.; BOIAGO, M.M.; SILVA, A.M.S.; MONTASSIER, H.J.; SOUZA, P.A.D. Características produtivas e imunológicas de frangos de corte submetidos a dietas suplementadas com cromo, criados sob diferentes condições de ambiente. Revista Brasileira de Zootecnia, v.41, p.11861192, 2012.

PAPPAS, A.C.; ZOIDIS, E.; SURAI, P.F.; ZERVAS, G. Selenoproteins and maternal nutrition. Comparative Biochemistry and Physiology, v.151, p.361-372, 2008. 
ROSTAGNO, H.S.; ALBINO, L.F.T.;

DONZELE, J.L. GOMES, P.C.;

OLIVEIRA, R.F.; LOPES, D.C.;

FERREIRA, A.S.; BARRETO, S.L.T.;

EUCLIDES, R.F. Tabelas brasileiras

para aves e suínos: composição de

alimentos e exigências nutricionais. $3 \mathrm{ed}$.

Viçosa: UFV, 2011. 252p.

SAAD, M.B. Efeito da suplementação de selênio orgânico na resposta

imunológica de frango de corte. 2009. Dissertação (Mestrado) - Universidade

Federal do Paraná, Curitiba.

SAS Institute. SAS/STAT: user's guide.

Version 6.11. Cary, 1996. 842p.

ZOIDIS, E.; PAPPAS, A.C.;

GEORGIOU, C.A.; KOMAITIS, E.;

FEGEROS, K. Selenium affects the

expression of GPx4 and catalase in the

liver of chicken. Comparative

Biochemistry and Physiology, v.155, p.294-300, 2010.

Data de recebimento: $14 / 04 / 2014$

Data de aprovação: 27/03/2015 